\title{
Synthesis and Characterization of Gefitinib and Paclitaxel Dual Drug Loaded Cockle Shell (Anadara granosa) Derived Calcium Carbonate Nanoparticles ${ }^{\dagger}$
}

\author{
S Chemmalar 1, Intan Shameha Abdul Razak 2, Che Azurahanim Che Abdullah 3, Nor Asma Ab Razak ${ }^{4}$ \\ Loqman Mohamad Yusof ${ }^{5}$ and Md Zuki bin Abu Bakar 6,*
}

Citation: Chemmalar, S.; Razak, I.S.A.; Abdullah, C.A.C.; Ab Razak, N.A.; Yusof, L.M.; Bakar, M.Z.b.A. Synthesis and Characterization of Gefitinib and Paclitaxel Dual Drug Loaded Cockle Shell (Anadara granosa) Derived Calcium Carbonate Nanoparticles. Proceedings 2021, 4 , 63. https://doi.org/10.3390/ IOCN2020-07801

Academic Editors: Ana María Díez-Pascual, Antonio Di Bartolomeo and Guanying Chen

Published: 15 November 2020

Publisher's Note: MDPI stays neutral with regard to jurisdictional claims in published maps and institutional affiliations.

Copyright: $\odot 2020$ by the authors. Licensee MDPI, Basel, Switzerland. This article is an open access article distributed under the terms and conditions of the Creative Commons Attribution (CC BY) license (http://creativecommons.org/licenses/by/4.0/).
1 Natural Medicines and Product Research Laboratory, Institute of Bioscience, Universiti Putra Malaysia (UPM),Serdang 43400, Selangor, Malaysia; gs52461@student.upm.edu.my

2 Department of Veterinary Preclinical Sciences, Faculty of Veterinary Medicine, UPM, Serdang 43400, Selangor, Malaysia; intanshameha@upm.edu.my

3 Biophysics Laboratory, Department of Physics, Faculty of Science, Laboratory of Cancer Research (MAKNA), Institute of Bioscience, and Material Synthesis \& Characterization Laboratory, Institute of Advanced Technology, UPM, Serdang 43400, Selangor, Malaysia; azurahanim@upm.edu.my

4 Natural Medicines and Product Research Laboratory, Institute of Bioscience, UPM, Serdang 43400, Selangor, Malaysia; norasmarazak@upm.edu.my

5 Department of Companion Animal Medicine and Surgery, Faculty of Veterinary Medicine, UPM, Serdang 43400, Selangor, Malaysia; loqman@upm.edu.my

6 Department of Veterinary Preclinical Sciences, Faculty of Veterinary Medicine, and Natural Medicines and Product Research Laboratory, Institute of Bioscience, UPM, Serdang 43400, Selangor, Malaysia

* Correspondence: zuki@upm.edu.my

+ Presented at the 2nd International Online-Conference on Nanomaterials, 15-30 November 2020; Available online: https://iocn2020.sciforum.net/.

Abstract: Calcium carbonate nanoparticles have salient properties, such as biocompatibility, pH responsiveness, and the ability to alkalinize a tumor, thereby reducing metastasis. A combination therapy regimen is normative for breast cancer, and besides its side effects, toxic vehicles are required for certain drugs. This study is aimed to transform the readily available Blood cockle shells (Anadara granosa) to calcium carbonate nanoparticles $\left(\mathrm{CSCaCO}_{3} \mathrm{NP}\right)$, loading them with Gefitinib (GEF) and Paclitaxel (PTXL). Facile top-down synthesis of $\mathrm{CSCaCO}_{3} \mathrm{NP}$ is comprised of grinding, sieving, and stirring with Tween 80, followed by filtration and finally dry milling for $120 \mathrm{~h}$. A ratio of $1+0.5: 25$ of GEF+PTXL: $\mathrm{CSCaCO}_{3} \mathrm{NP}$ in an equal admixture of DMSO and 0.05\% Tween 80 buffer was used for drug loading. Loading content (\%) and encapsulation efficiency (\%) for GEF and PTXL in dual drug-loaded NP (GEF-PTXL-CSCaCO ${ }_{3} \mathrm{NP}$ ) was $1.98 \pm 0.11,50.01 \pm 2.18$ and $0.92 \pm 0.01,45.60$ \pm 0.32 . Field emission scanning electron micrographs revealed that the nanoparticles were almost spherical with the average diameter $(\mathrm{nm})$ measuring $63.96 \pm 22.3$ and $87.20 \pm 26.66$ for $\mathrm{CSCaCO}_{3} \mathrm{NP}$, and GEF-PTXL-CSCaCO ${ }_{3} \mathrm{NP}$, respectively. The Dynamic Light Scattering data gives the average diameter of $\mathrm{CSCaCO}_{3} \mathrm{NP}$ and GEF-PTXL-CSCaCO${ }_{3} \mathrm{NP}$ as $179 \pm 10.9(\mathrm{~nm})$, and $274 \pm 23.22(\mathrm{~nm})$, and Zeta potential was $-17 \pm 1.15(\mathrm{mV})$ and $-10.30 \pm 1.7(\mathrm{mV})$, respectively. Fourier-transform Infrared spectroscopy proves that $\mathrm{CSCaCO}_{3} \mathrm{NP}$ have been loaded with the drugs. X-Ray Diffraction data indicate that the aragonite phase is unaltered. $\mathrm{N}_{2}$ adsorption-desorption isotherms reveals that $\mathrm{CSCaCO}_{3} \mathrm{NP}$ are mesoporous and that the surface area was reduced from $10.68 \pm 0.22$ to $9.88 \pm 0.24$ $\mathrm{m}^{2} / \mathrm{g}$ after drug loading. For the first time, this work will describe the process that enabled to synthesize $\mathrm{CSCaCO}_{3} \mathrm{NP}$, which was used as a carrier to load GEF and PTXL and its salient characteristics.

Keywords: calcium carbonate nanoparticles; Gefitinib; Paclitaxel; dual drug loading; XRD; FTIR; mesoporous 


\section{Introduction}

Blood cockle shells (Anadara granosa) are bivalve shellfish that grow along the shallow waters of the coastline of southeast Asia, east Asia, and south Asia including Malaysia $[1,2]$. Cockle shell derived inorganic calcium carbonate nanoparticles $\left(\mathrm{CSCaCO}_{3} \mathrm{NP}\right)$ have been in focus in recent years due to its physicochemical and biocompatible properties. Their availability, low cost, safety, biocompatibility, $\mathrm{pH}$-sensitive property, and slow biodegradability makes $\mathrm{CSCaCO}_{3}$ nanoparticles the right candidate to be nominated as the preferred drug delivery system. In the past various drugs have been successfully loaded onto $\mathrm{CaCO}_{3} \mathrm{NP}$ ranging from hormones [3], antibiotics [4], to even chemotherapeutic drugs [5]. Dual drug-carrying nanoparticles have more advantages since the nanoparticles help in improving the problem of solubility of hydrophobic drugs by carrying them and releasing them mostly at the tumor milieu. Paclitaxel (PTXL) and Gefitinib (GEF) are the two hydrophobic drugs aimed to be loaded together onto the $\mathrm{pH}$-dependent $\mathrm{CSCaCO}_{3} \mathrm{NP}$. The $\mathrm{CSCaCO}_{3} \mathrm{NP}$ decomposes slowly in the normal physiological $\mathrm{pH}(7.4)$ while decomposing more quickly in the acidic $\mathrm{pH}(<6.5)$ of the tumor environments [6]. When designing novel drug delivery systems, the physicochemical characterization of nanoparticles is very essential in determining their long-term stability and also their biological effects on tissues [7]. The major parameters required for physicochemical characterization of nanomaterials are shape, size, poly dispersive index, surface charge, composition, and purity [8].

\section{Methods}

The synthesis of $\mathrm{CSCaCO}_{3} \mathrm{NP}$ is comprised of two major steps. The first step was the synthesis of microparticles from cockle shells [9]. The second step was preparing a suspension with $2 \mathrm{~g}$ of the $75-\mu \mathrm{m}$ of $\mathrm{CSCaCO}_{3}$ powder with $20 \mathrm{~mL}$ of deionized water and 1 $\mathrm{mL}$ of Tween 80 . This suspension was stirred at $1000 \mathrm{rpm}$ for $2 \mathrm{~h}$ and filtered. The filtrate was centrifuged for $10 \mathrm{~min}$ at 14,000 rpm and the supernatant was discarded. The pellet was dispersed upon the addition of $20 \mathrm{~mL}$ deionized water and then washed twice with deionized water. The collected nanoparticles were dried and then ball milled at $120 \mathrm{rpm}$ for $120 \mathrm{~h}$. The resultant particles $\left(\mathrm{CSCaCO}_{3} \mathrm{NP}\right)$ were characterized before loading the drugs.

For synthesizing dual drug loaded GEF-PTXL-CSCaCO $3{ }_{3} \mathrm{NP}$, three groups, namely GEF1-PTXL, GEF2-PTXL, and GEF3-PTXL were assigned with concentration of GEF and PTXL being $400 \mu \mathrm{g}+200 \mu \mathrm{g}$, and varying concentrations of $\mathrm{CSCaCO}_{3} \mathrm{NP} 10,000 \mu \mathrm{g}, 15,000$ $\mu \mathrm{g}$, and 20,000 $\mu \mathrm{g}$, respectively. PTXL and GEF dissolved in DMSO were added to $5 \mathrm{~mL}$ of $\mathrm{CSCaCO}_{3} \mathrm{NP}$ suspension prepared with $0.05 \%$ Tween 80 buffer and DMSO in a 50:50 $(\mathrm{v} / \mathrm{v})$ ratio. The loading was achieved by continuous stirring at $200 \mathrm{rpm}$ overnight at room temperature. The individual suspensions were centrifuged at 14,000 rpm for $10 \mathrm{~min}$, followed by washing the pellet with deionized water and drying. The supernatant obtained after centrifugation contained the un-entrapped GEF and PTXL, which was used to indirectly determine the amount of drug-loaded onto the nanoparticles using UV-Vis spectrophotometer. The encapsulation efficiency (EE\%) and loading content (LC\%) were determined as the average measurement of 3 independent measurements[10].

Physicochemical characterization of $\mathrm{CSCaCO}_{3} \mathrm{NP}$ and GEF-PTXL-CSCaCO $\mathrm{NP}_{3}$ were conducted by High resolution Transmission electron microscopy (HR-TEM), Field emission Scanning electron microscopy (FESEM), Zeta potential and hydrodynamic diameter detection, Powder X-ray diffraction (PXRD), Fourier-transform infra-red spectroscopy (FT-IR) and BET analysis. For HR-TEM, the sample was added to $3 \mathrm{~mL}$ of $100 \%$ acetone and sonicated for $30 \mathrm{~min}$. A drop of the sonicated solution was placed onto a carboncoated copper grid and excess fluid was wicked off with a filter paper, followed by drying at room temperature for an hour and examined. For FESEM, the sample was dispersed onto $12 \mathrm{~mm}$ diameter aluminum sample holders using conductive carbon paint and then coated with the Platinum layer under vacuum and examined. These images were analyzed using ImageJ software. For Zeta potential, Polydispersity Index, and Hydrodynamic diameter analysis, $0.4 \mathrm{mg}$ of the sample was dispersed in $15 \mathrm{~mL}$ deionized water and then 
sonicated for $30 \mathrm{~min}$. After sonication, the sample was again double diluted with deionized water. Then, the sample was injected into disposable cuvettes, and hydrodynamic diameter along with the Poly-dispersity Index were measured using Zetasizer Nano ZS (Ver.7.11; Malvern Instruments Ltd., Malvern, UK). All measurements were also carried out in duplicate of three independent experiments. PXRD patterns were obtained using the Shimadzu XRD-6000 powder diffractometer configured with $\mathrm{Cu}$ X-ray tube with $1.540562 \AA$. The samples were scanned at the rate of $40 / \mathrm{min}$ with diffraction angles from $4.0207^{\circ}$ to $89.9527^{\circ}$ at room temperature. The data were analyzed with $X^{\prime}$ pert HighScore Plus software. The samples were investigated using the Fourier infrared spectrophotometer (Model 100 series, Perkin Elmer, Shelton, CT, USA) over the range of 4000 to $400 \mathrm{~cm}^{-1}$ at a $2 \mathrm{~cm}^{-1}$ resolution and averaging $64 \mathrm{scans} / \mathrm{s}$. The obtained data were analyzed with OriginPro 9.0. For determining the surface area, nitrogen absorption and desorption experiments were carried out with Micromeritics. The generated data were analyzed using BET (Brunauer-Emmett-Teller) and BJH (Barrett-Joyner-Halenda) models to determine the BET specific surface area and BJH mean pore size. Statistics were calculated using OriginPro 9.0, and Microsoft excel (Microsoft, Redmond, WA, USA) for analyzing the mean and SD.

\section{Results and Discussion}

The structural integrity and physicochemical properties of intact nanoparticles must be preserved throughout the formulation process until the finished product. Milling technology has been applied to synthesize poorly water-soluble compounds [11]. The current top-down technique, used to synthesize the $\mathrm{CSCaCO}_{3} \mathrm{NP}$ from the cockle shell is laborious. On the other hand, this method is more effective and less expensive than the use of a high-pressure homogenizer technique via a microemulsion system to synthesize $\mathrm{CSCaCO}_{3} \mathrm{NP}$ by Kamba et al. [12].

The method followed for loading the drugs is facile and efficient. Drug-loading and drug-encapsulation percentages are very vital parameters in the synthesis of nanomedicines [13]. The Loading content and encapsulation efficiency of the three groups are tabulated (Table 1). Loading content (\%) and encapsulation efficiency (\%) for GEF and PTXL for GEF1-PTXL was $1.98 \pm 0.11,50.01 \pm 2.18$ and $0.92 \pm 0.01,45.60 \pm 0.32$. GEF1-PTXL is a suitable group, since it possesses higher encapsulation efficiency and the highest loading content of GEF, and PTXL, respectively. The loading of drugs into the nanoparticles is also governed by the surface area available on the $\mathrm{CSCaCO}_{3}$ nanoparticles. Another important factor is the water solubility of the drugs employed [14]. The lower loading content of less than $10 \%$ is usually observed for inorganic carrier-based nanoparticles [13]. A similar result is reflected in the loading content obtained in the current experiment. In addition to the above-stated facts, other factors to be considered for lower values are the physical and electrostatic interactions during the drug loading process. The $\mathrm{CSCaCO}_{3} \mathrm{NP}$ is negatively charged, and so will contribute to electrostatic repulsion leading to lower loading content. The obtained encapsulation efficiency can be compared to the data obtained by lbiyeye et al. where $\mathrm{CSCaCO}_{3} \mathrm{NP}$ was loaded with Thymoquinone/Doxorubicin, and the obtained values of this study follow a similar trend [15]. The observed trend in the encapsulation efficiency (\%) for $\mathrm{CSCaCO}_{3} \mathrm{NP}$ was similar to the data obtained for single drug loading like Doxorubicin [3,5,7] and Docetaxel [5] loaded onto the same type of cockle shell-derived $\mathrm{CaCO}_{3} \mathrm{NP}$, but the loading content is lower in this study, when compared to other research. 
Table 1. Loading content (\%) and Encapsulation efficiency (\%) of various groups of GEF-PTXL-CSCaCO ${ }_{3} \mathrm{NP}$.

\begin{tabular}{|c|c|c|c|c|}
\hline Groups & Drugs & $\mathrm{CSCaCO}_{3} \mathrm{NP}(\mu \mathrm{g})$ & Loading Content (\%) & Encapsulation Efficiency (\%) \\
\hline \multirow{2}{*}{ GEF1-PTXL } & GEF $(400 \mu \mathrm{g})$ & \multirow{2}{*}{10,000} & $1.98 \pm 0.11$ & $50.01 \pm 2.18$ \\
\hline & PTXL $(200 \mu g)$ & & $0.92 \pm 0.01$ & $45.60 \pm 0.32$ \\
\hline \multirow{2}{*}{ GEF2-PTXL } & GEF $(400 \mu \mathrm{g})$ & \multirow{2}{*}{15,000} & $1.14 \pm 0.23$ & $42.95 \pm 8.98$ \\
\hline & PTXL $(200 \mu \mathrm{g})$ & & $0.50 \pm 0.08$ & $37.45 \pm 5.73$ \\
\hline \multirow{2}{*}{ GEF3-PTXL } & GEF $(400 \mu \mathrm{g})$ & \multirow{2}{*}{20,000} & $1.12 \pm 0.19$ & $45.03 \pm 10.37$ \\
\hline & 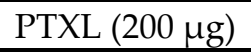 & & $0.44 \pm 0.08$ & $43.93 \pm 7.25$ \\
\hline
\end{tabular}

The TEM micrographs of $\mathrm{CSCaCO}_{3} \mathrm{NP}$ demonstrated a spherical shape and a size of $52.36 \pm 15.82 \mathrm{~nm}$ (Figure 1a). The FESEM micrographs of $\mathrm{CSCaCO}_{3} \mathrm{NP}$ revealed particles of $63.96 \pm 22.3 \mathrm{~nm}$ and GEF-PTXL-CSCaCO${ }_{3} \mathrm{NP}$ exhibited spherical shape and relatively uniform size of $87.20 \pm 26.66 \mathrm{~nm}$. (Figure 1b). This size is comparable to the results of Ibiyeye et al. [15]. The zeta potential of the $\mathrm{CSCaCO}_{3} \mathrm{NP}$ was $-17 \pm 1.15(\mathrm{mV})$ and GEFPTXL-CSCaCO ${ }_{3} \mathrm{NP}$ was $-10.30 \pm 1.7(\mathrm{mV})$ (Figure 1c). The negative Zeta potential is in concurrence with other works [4,5], and the poly-dispersity index (PDI) was on average 0.3 for both the nanoparticles (Figure 1c). The Hydrodynamic diameters of $\mathrm{CSCaCO}_{3} \mathrm{NP}$ and GEF-PTXL-CSCaCO 3 NP are $179 \pm 10.9(\mathrm{~nm})$ and $274 \pm 23.22(\mathrm{~nm})$, respectively (Figure 1c), which was larger than the Doxorubicin loaded $\mathrm{CSCaCO}_{3} \mathrm{NP}$ obtained by Danmaigoro et al. [16] and Hamidu et al. [17]. The overestimation of the hydrodynamic diameter from DLS was upto 17 to $31 \%$, when compared with the values from the electron micrographs $[4,16,17]$. This type of discrepancy has been observed as the methods used to measure the size is different. Another vital point to be noted is that the dispersant used for the DLS measurement also plays a role in altering the values [18], the aggregation or opsonization of particles in the deionized water medium [19], as compared to TEM, where the particles were measured in a dry state.

PXRD patterns of $\mathrm{CSCaCO}_{3} \mathrm{NP}$ and GEF-PTXL-CSCaCO${ }_{3} \mathrm{NP}$ indicate that both the nanoparticles possess aragonite crystalline signature (Figure 1d), and showed the highest score with that of the aragonite phase of $\mathrm{CaCO}_{3}$. This results are in agreement with other researchers where various drugs, like Vancomycin [20], Doxorubicin [16], Thymoquinone, and Doxorubicin [15] were loaded onto $\mathrm{CSCaCO}_{3} \mathrm{NP}$. FT-IR spectra is a result of the absorption of electromagnetic radiations at frequencies that correlate to the vibration of a specific set of chemical bonds form within a molecule [21]. The FT-IR spectra of $\mathrm{CSCaCO}_{3} \mathrm{NP}$ demonstrated vibrational band assignments at 1445, 1084, 856, and $714 \mathrm{~cm}^{-1}$ (Figure 1e). The largest and strongest band exhibited at $1445 \mathrm{~cm}^{-1}$ is attributed to the C-O stretching band. Other peaks at 1084 and $856 \mathrm{~cm}^{-1}$ are attributed to $\mathrm{CO}_{3}{ }^{2-}$ in the molecular structure of the calcium carbonate. The derived spectra are similar to the spectra obtained by other researchers for cockle shell derived $\mathrm{CaCO}_{3} \mathrm{NP}$ [16]. The spectral absorption peaks of GEF-PTXL-CSCaCO 3 NP demonstrated new vibrational band assignments at 952.84 (cyclohexane), 1024.20 (C-F stretch), 2918.30 (C-H stretching) and 3435.22 (aromatic amine and $\mathrm{OH}^{-}$stretch) $\mathrm{cm}^{-1}[22,23]$ (Figure 1e). The largest and strongest band exhibited by $\mathrm{CSCaCO}_{3} \mathrm{NP}$ at $1445 \mathrm{~cm}^{-1}$ remained unaltered in spectra of GEF-PTXL-CSCaCO $3 \mathrm{NP}$, indicating that the alkyl group is unaffected. All these changes indicate that the drugs are adsorbed onto the nanoparticles. 


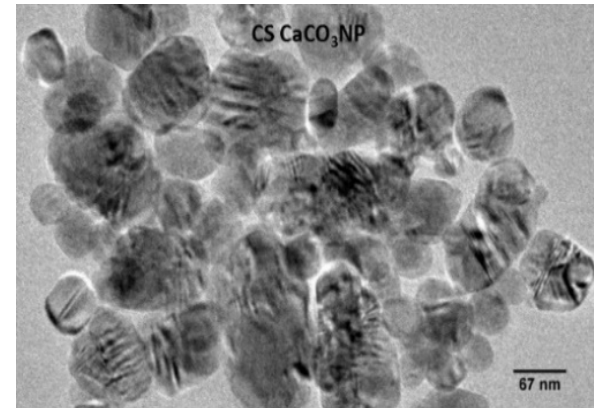

(a)

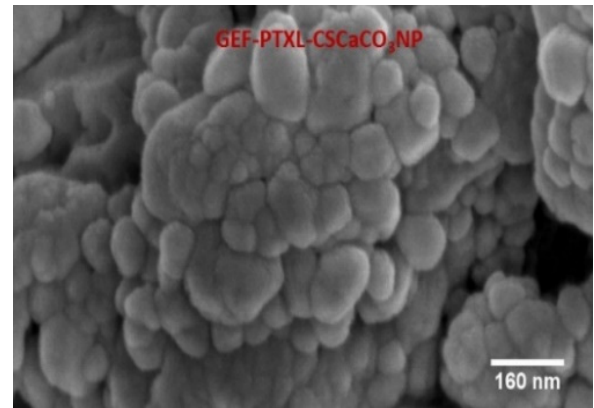

(b)

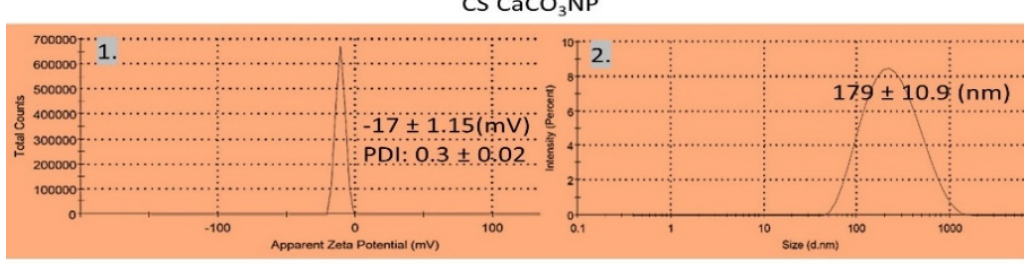

GEF-PTXL-CSCaCO${ }_{3} \mathrm{NP}$

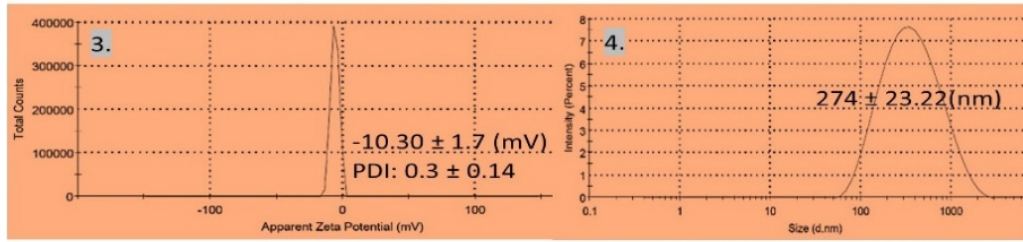

(c)

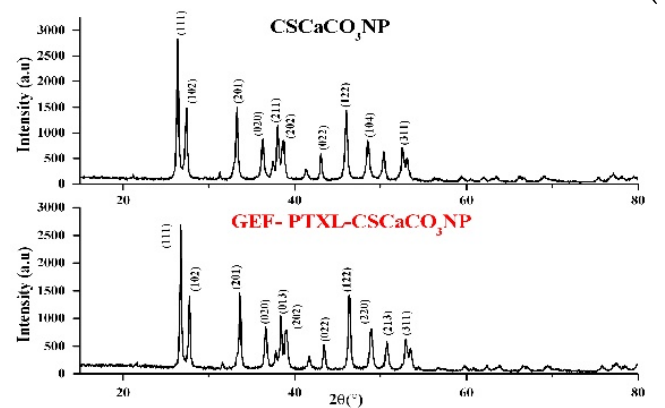

(d)

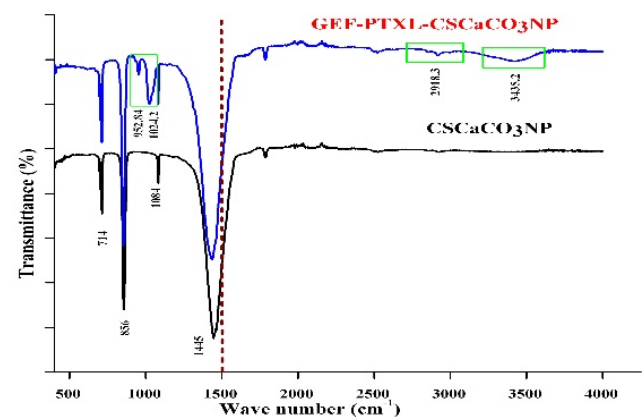

(e)

Figure 1. Characteristics of $\mathrm{CSCaCO}_{3} \mathrm{NP}$ and $\mathrm{GEF}^{-} \mathrm{PTXL}-\mathrm{CSCaCO}_{3} \mathrm{NP}$ (a) TEM micrograph of $\mathrm{CSCaCO}_{3} \mathrm{NP}$ with $50 \mathrm{~nm}$ particles of spherical shape and relatively even size; (b) FESEM micrograph of GEF-PTXL-CSCaCO ${ }_{3} \mathrm{NP}$ with $87 \mathrm{~nm}$ on average and relatively spherical shape and (c) Zeta Potential, Particle size distribution (1), and hydrodynamic diameter (2) of $\mathrm{CSCaCO}_{3} \mathrm{NP}$, and Zeta Potential, Particle size distribution (3), and hydrodynamic diameter (4) of GEF-PTXL-CSCaCO $3 \mathrm{NP}^{-}$; (d) PXRD patterns demonstrates aragonite crystalline phase in both the nanoparticles and labelled are the miller indices planes of the synthesized crystals; (e) FT-IR pattern of $\mathrm{CSCaCO}_{3} \mathrm{NP}$ and formation of new peaks (green box) in the spectra of GEF-PTXL-CSCaCO${ }_{3} \mathrm{NP}$.

From the Nitrogen adsorption and desorption experiments, the isotherm obtained for $\mathrm{CSCaCO}_{3} \mathrm{NP}$ and the GEF-PTXL-CSCaCO${ }_{3} \mathrm{NP}$ is Type IV, based on the classification of BET system. This type of isotherm is characterized by the "hysteresis loop," where, capillary condensation occurs, with an initial loop formed by the mono-multi layer adsorption, a 2nd loop by the desorption of gases. This type of isotherm indicates that the nanoparticles are mesoporous [24,25]. The H1 hysteresis loop is formed when the adsorption and desorption curves are almost vertical and approximately parallel to each other and it signifies the presence of pores with cylindrical geometry and uniform pore size. The surface area of the synthesized $\mathrm{CSCaCO}_{3} \mathrm{NP}$ and GEF-PTXL-CSCaCO${ }_{3} \mathrm{NP}$ are $10.68 \pm$ 0.22 and $9.88 \pm 0.24\left(\mathrm{~cm}^{2} / \mathrm{g}\right)$, which is higher than the surface area obtained by Danmaigoro et al. [16] and Hammadi et al. [5]. The BJH mean pore size diameter of the synthesized 
$\mathrm{CSCaCO}_{3} \mathrm{NP}$ and GEF-PTXL-CSCaCO${ }_{3} \mathrm{NP}$ was 5.21 and $5.23(\mathrm{~nm})$, which is slightly higher than the pore size obtained by Danmaigoro et al. [16].

\section{Conclusions}

In conclusion, the simple blood cockle shells, a by-product of the food industry, was converted into a potential nanoparticulate drug carrier. The blood cockle shell-derived $\mathrm{CaCO}_{3} \mathrm{NP}$ is purely aragonite, porous, and contains a large surface area compared to the particle size. Specifically, in this work, we have proved that cockle shell-derived $\mathrm{CaCO}_{3} \mathrm{NP}$ can be loaded with chemotherapeutic drugs. After loaded with Gefitinib and Paclitaxel, the physicochemical characterization data revealed that the drugs were successfully loaded onto the nanoparticles and the aragonite phase of the cockle shell-derived $\mathrm{CaCO}_{3} \mathrm{NP}$ has remained unaltered.

\section{Institutional Review Board Statement: Not applicable.}

Informed Consent Statement: Not applicable.

Data Availability Statement: All relevant data are contained within this manuscript.

Acknowledgments: This research was funded by MINISTRY OF HIGHER EDUCATION MALAYSIA, under the Fundamental Research Grant Scheme (FRGS/1/2019/SKK15/UPM/02/4). The views and opinion presented by the authors do not reflect those of the Fundamental research grant scheme under Government of Malaysia.

\section{References}

1. Faulkner, P. Morphometric and taphonomic analysis of granular ark (Anadara granosa) dominated shell deposits of Blue Mud Bay, northern Australia. J. Archaeol. Sci. 2010, 37, 1942-1952, doi:10.1016/j.jas.2010.02.021.

2. FAO. Aquatic Species Distribution Map Viewer. Fish. Aquac. Dep. Available online: http://www.fao.org/figis/geoserver/factsheets/species.html\%0A (accessed on 6 August 2020).

3. Jaji, A.Z.; Zakaria, Z.; Mahmud, R.; Loqman, M.Y.; Hezmee, M.N.M.; Isa, T.; Fu, W.; Hammadi, N.I. Synthesis, characterization, and cytocompatibility of potential cockle shell aragonite nanocrystals for osteoporosis therapy and hormonal delivery. Nanotechnol. Sci. Appl. 2017, 10, 23-33, doi:10.2147/NSA.S113030.

4. Idris, S.B.; Kadir, A.A.; Jesse, F.F.A.; Ramanoon, S.Z.; Basit, M.A.; Zakaria, Z.A.; Zakaria, M.Z.A.B. Synthesis, characterization, and in vitro release of oxytetracycline loaded in $\mathrm{pH}$-responsive $\mathrm{CaCO}_{3}$ nanoparticles. J. Appl. Pharm. Sci. 2019, 9, 19-27 doi:10.7324/JAPS.2019.91103.

5. Hammadi, N.I.; Abba, Y.; Hezmee, M.N.M.; Razak, I.S.A.; Jaji, A.Z.; Isa, T.; Mahmood, S.K.; Zakaria, M.Z.A.B. Formulation of a Sustained Release Docetaxel Loaded Cockle Shell-Derived Calcium Carbonate Nanoparticles against Breast Cancer. Pharm. Res. 2017, 34, 1193-1203, doi:10.1007/s11095-017-2135-1.

6. Maleki Dizaj, S.; Barzegar-Jalali, M.; Zarrintan, M.H.; Adibkia, K.; Lotfipour, F. Calcium carbonate nanoparticles as cancer drug delivery system. Expert Opin. Drug Deliv. 2015, 12, 1649-1660, doi:10.1517/17425247.2015.1049530.

7. Hosokawa, M.; Nogi, K.; Naito, M.; Yokoyama, T. Basic properties and measuring methods of nanoparticles. In Nanoparticle Technology Handbook, 1st ed.; Hosokawa, M., Nogi, K., Naito, M., Yokoyama, T., Eds.; Elsevier: Amsterdam, Netherlands, 2007; pp. $1-166$.

8. Crist, R.M.; Grossman, J.H.; Patri, A.K.; Stern, S.T.; Dobrovolskaia, M.A.; Adiseshaiah, P.P.; Clogston, J.D.; McNeil, S.E. Common pitfalls in nanotechnology: Lessons learned from NCI's Nanotechnology Characterization Laboratory. Integr. Biol. 2013, 5, 66-73, doi:10.1039/c2ib20117h.

9. Islam, K.N.; Ali, M.E; Bakar, M.Z.B.A.; Loqman, M.Y.; Islam, A.; Islam, M.S.; Rahman, M.M.; Ullah, M. A novel catalytic method for the synthesis of spherical aragonite nanoparticles from cockle shells. Powder Technol. 2013, 246, 434-440, doi:10.1016/j.powtec.2013.05.046.

10. Fu, W.; Noor, M.M.H.; Yusof, L.M.; Ibrahim, T.A.T.; Keong, Y.S.; Jaji, A.Z.; Zakaria, M.Z.A.B. In vitro evaluation of a novel pH sensitive drug delivery system based cockle shell-derived aragonite nanoparticles against osteosarcoma. J. Exp. Nanosci. 2017, 8080, 1-22, doi:10.1080/17458080.2017.1287965.

11. Chen, H.; Khemtong, C.; Yang, X.; Chang, X.; Gao, J. Nanonization strategies for poorly water-soluble drugs. Drug Discov. Today 2011, 16, 354-360, doi:10.1016/j.drudis.2010.02.009.

12. Kamba, A.S.; Ismail, M.; Tengku Ibrahim, T.A.; Ibrahim, T.; Zakaria, Z.A.B.A. pH-Sensitive, Biobased Calcium Carbonate Aragonite Nanocrystal as a Novel Anticancer Delivery System. Biomed. Res. Int. 2013, 2013, 1-10, doi:10.1155/2013/587451.

13. Shen. S.; Wu, Y.; Liu, Y.; Wu, D. High drug-loading nanomedicines: Progress, current status, and prospects. Int. J. Nanomed. 2017, 12, 4085-4109, doi:10.2147/IJN.S132780. 
14. Govender, T.; Riley, T.; Ehtezazi, T.; Garnett, M.C.; Stolnik, S.; Illum, L.; Davis, S.S. Defining the drug incorporation properties of PLA-PEG nanoparticles. Int. J. Pharm. 2000, 199, 95-110, doi:10.1016/s0378-5173(00)00375-6.

15. Ibiyeye, K.M.; Zakaria, M.Z.A.B.; Nurdin, N.; Mokrish, A. Combine Drug Delivery of Thymoquinone-Doxorubicin by Cockle Shellderived pH-sensitive Aragonite $\mathrm{CaCO}_{3}$ Nanoparticles. Nanosci. Nanotechnol. Asia 2020, 10, 518-533, doi:10.2174/2210681209666190508122540.

16. Danmaigoro, A.; Selvarajah, G.T.; Noor M.H.M.; Mahmud, R.; Zakaria, M.Z.A.B. Development of Cockleshell (Anadara granosa) Derived CaCO 3 Nanoparticle for Doxorubicin Delivery. J. Comput. Theor. Nanosci. 2017, 14, 5074-5086, doi: 10.1166/jctn.2017.6920

17. Hamidu, A.; Mokrish, A.; Mansor, R.; Razak, I.S.A.; Danmaigiro, A.; Jaji, A.Z.; Zakaria, M.Z.A.B. Modified methods of nanoparticles synthesis in $\mathrm{pH}$-sensitive nano-carriers production for doxorubicin delivery on MCF-7 breast cancer cell line. Int. J. Nanomed. 2019, 14, 3615-3627, doi: 10.2147/IJN.S190830

18. Souza, T.G.F.; Ciminelli, V.S.T.; Mohallem, N.D.S. A comparison of TEM and DLS methods to characterize size distribution of ceramic nanoparticles. J. Phys. Conf. Ser. 2016, 733, 1-5, doi: 10.1088/1742-6596/733/1/012039.

19. Gaumet, M.; Vargas, A.; Gurny, R.; Delie, F. Nanoparticles for drug delivery: The need for precision in reporting particle size parameters. Eur. J. Pharm. Biopharm. 2008, 69, 1-9, doi:10.1016/j.ejpb.2007.08.001.

20. Saidykhan, L.; Rukayadi, Y.; Umar Kura, A.; Yazan, L.S.; Zakaria, M.Z.A.B Development of nanoantibiotic delivery system using cockle shell-derived aragonite nanoparticles for treatment of osteomyelitis. Int. J. Nanomed. 2016, 11, 661, doi:10.2147/IJN.S95885.

21. Coates, J. Interpretataion of Infrared Spectra, A Practical approach. In Encycolpedia of Analytical Chemistry; Meyers, R.A., Ed.; John Wiley \& Sons, Ltd.: Chichester, UK, 2000; pp. 10815-10837.

22. Renuga Devi, T.S.; Gayathri, S. FTIR and FT-Raman spectral analysis of Paclitaxel drugs. Int. J. Pharm. Sci. Rev. Res. 2010, 2, 106-110.

23. Talari, A.C.S.; Martinez, M.A.G.; Movasaghi, Z.; Rehman, S.; Ur Rehman, I. Advances in Fourier transform infrared (FTIR) spectroscopy of biological tissues. Appl. Spectrosc. Rev. 2017, 52, 456-506, doi:10.1080/05704928.2016.1230863.

24. Sing, K.S.W. Reporting Physiosorption data for gas/solid systems with special Reference to the Determination of Surface Area and Porosity. Pure Appl. Chem. 1982, 54, 2201-2218.

25. Thommes, M.; Kaneko, K.; Neimark, A.V.; Oliver, J.P.; Rodriguez-Reinoso, F.; Rouquerol, J.; Sing, K.S.W. Physisorption of gases, with special reference to the evaluation of surface area and pore size distribution (IUPAC Technical Report). Pure Appl. Chem. 2015, 87, 1051-1069. 